\title{
PROCEDURE OF INSERTING RH GIRDER METHOD IN ROAD UNDER BRIDGE
}

\author{
Ranjeet. P $^{1}$, D.V.S. Narshima Rao ${ }^{2}$, Md. Akram Ullah Khan ${ }^{3}$ \\ ${ }^{1}$ Assistant Professor, Civil Department, GNITC, Telangana, India. \\ ${ }^{2}$ Assistant Professor, Civil Department, GNITC, Telangana, India. \\ ${ }^{3}$ Assistant Professor, Civil Department, GNITC, Telangana, India.
}

\begin{abstract}
The intersection of railway track and the road at the same level is referred to a level crossing. In the urban areas the level crossing are generally monitored by qualified railway personnel. At level crossing we use many techniques to solve the problem where road traffic and railway traffic meat at one pace. Road under bridge and road over bridge are considered as solutions for avoiding level crossings of roads and railway track. Here we use the best method to solve the problem at urban places where road and railway track intersect is $R H$ Girder method.
\end{abstract}

Keywords: RH Girder, Girder, Level Crossing, Road Over Bridge and RUB etc...

\section{INTRODUCTION}

This technique is similar to cut and cover method except in the sense that RH girder is inserted because of less duration of availability of traffic block and the boxes are inserted under running traffic.

\section{GIRDER}

It is a beam it may be with steel, wood or reinforced, used to main horizontal supports in bridges or building.

A girder bridge is a bridge built on two foundations piers placed ether sides of road or railway track. it is built to carry out the traffic without disturbing the road or railway traffic.

it is also known as beam bridges, the most common and simplest type of bridge.

It consists of a horizontal beam supported at each end by a pier or other similar structure.

Longer girder bridges must be supported along their span by additional structures.

Girder bridges are typically used over short to medium distances.

\subsection{Types of Girder}

1. I beam Girder

2. Box Girder.

3. Plate Girder.

4. Concrete Girder

\subsubsection{I-Beam Girder}

I-beam girders are among the most commonly used girders in bridge construction.
I-beam girders are made from rolled steel, in constructions bridges are used I beam which are called rolled steel girder bridge

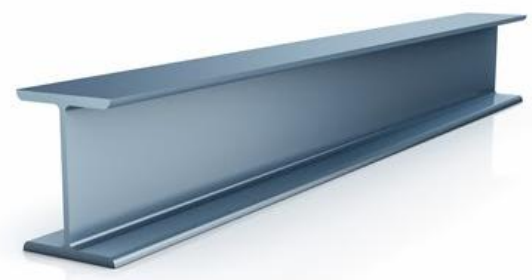

I-beam girder is very economical and simple in design and it forwards the relatively strength to build.

If the bridges have any curves, the beam is subjected to get twisting force which is also called as torque I beam.

\subsubsection{Box Girder}

Box girders are often used in the construction of roadway flyovers and elevated bridges for light rail transport.

Box girders are more costly than I-beams and not as easy to build. However, they do have some important advantages.

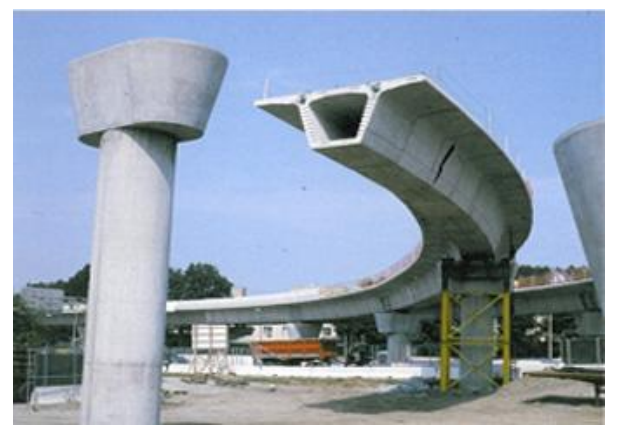


Box girders are also more effective and also have good strength than I-beams over longer spans.

Box girder mainly used in Road over bridges which helps to complete the construction fast.

\subsubsection{Plate Girder}

Plate girders became popular in the late 1800s when they were used in the construction of railroad bridges.

Flat steel sections were initially riveted or bolted together to obtain the desired overall span.

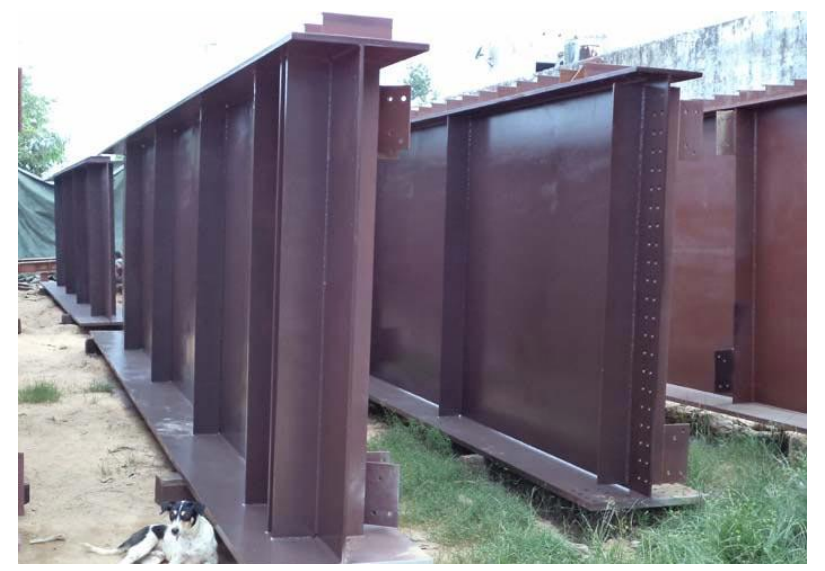

In the 1950s, welding became the preferred method of joining the large steel sections. This was a more economical and efficient construction method, and also allowed the construction of more aesthetically pleasing bridges

\subsubsection{Concrete Girder}

A concrete girder is a pre stressed mould which is made to get into the shape of I beam. This is also reinforced with steel rods to get the correct strength.

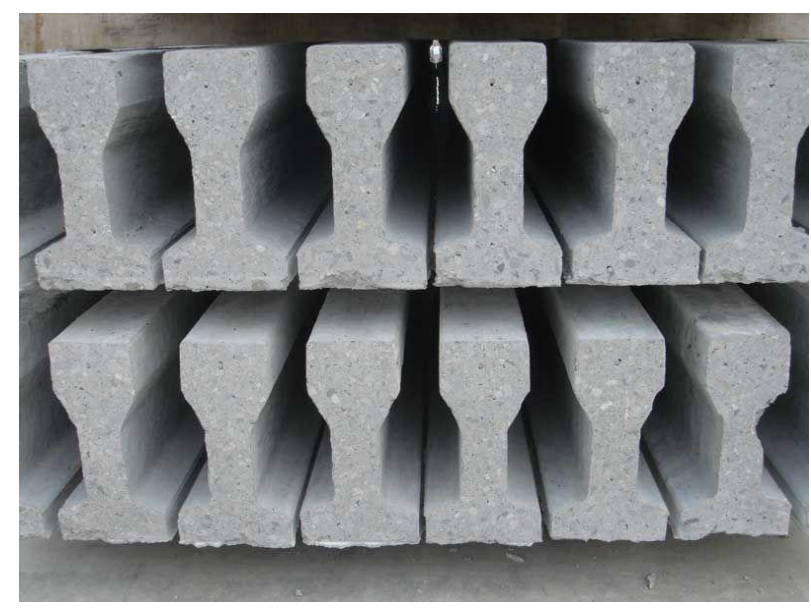

This combination is particularly effective in construction. The concrete withstands the strength or force of compression walls and the steel rods embedded the force of tension.

Concrete is also one of the cheapest construction materials.

\section{THE VARIOUS STAGES INVOLVED IN THE CONSTRUCTION OF AN UNDERPASS BY THIS TECHNIQUE}

Step1: A PCC bed is cast adjacent to the Railway embankment at the required level. Generally the top bed is $50 \mathrm{~mm}$ below, which is later finished with screening layer to obtain a perfect level surface. This PCC bed serves the purpose of forming the base to the casting of the box segments.

Step2: Over this well set and leveled PCC bed, the RCC box segments are cast. The boxes are cast in segments depending upon the barrel length and availability of suitable capacity of crane. After all the box segments are casted and cured, preliminary arrangements like position of crane arrangements, availability of labor, procurement of tools and plants required for delinking of track, availability of welding equipment, lighting arrangements, prior information to the other concerned departments like operating, commercial, S\&T, Railtel and electrical depts. and duration of block required to complete the work in all respects including linking of track.

Step3: The existing cables of S\&T, Railtel and electrical departments are properly secured and the rails at required location are cut before starting of the work. After obtaining the required traffic block, the rails are cut by welding and kept aside. The existing bank is demolished / dismantled up to the required bed level. After reaching the required depth, the bed is made level and uniform.

Step4: After the bed is made leveled and uniform, a sleeper matting and crib staging arrangement is prepared for placing of RH girder. Necessary packing plates and wooden blocks are also used to avoid lateral and longitudinal movement of the RH girder. The rail joints are welded and the levels checked. The track parameters are closely monitored during the entire process and any defect attended immediately by a special PWI gang. After performing the above operation, the trains are run with restricted speed.

Step5: A PCC bed is cast where the boxes are required to be placed with rails embedded in the bed. The RCC box segments already casted are rolled / pushed by means of a suitable crane and placed in position. All the boxes are placed in similar manner. The alignment and the bed levels of the RCC boxes are monitored by optical instruments at regular intervals. When the entire operation of placing of RCC box segments is completed i.e. after all segments have reached their final positions, the gaps between adjacent box segments and the interspaces between box and ground are grouted.

Step6: The next step involved after placing of RCC box segments is now to remove the inserted RH girder. By duly taking the block, informing to all concerned and making preliminary arrangements, the inserted $\mathrm{RH}$ girder is removed, crib staging and sleeper matting is removed. The 
required depth from top of slab to bottom of sleeper is made up by filling up of earth and the required cushion of ballast. The rail panel with fittings already prepared is lifted and placed in position by means of crane. The rail joints are welded and the levels checked. The track parameters are closely monitored during the entire process and any defect attended immediately by a special PWI gang. Finishing works such as return walls, wing walls, wearing coat, roadway and approaches are completed and Underpass commissioned.

\section{METHOD WHICH ARE RECOMMENDED}

- In high traffic density routes

- where duration of block available is very less

- when rock is encountered during cut and cover method

\section{THE VARIOUS STAGES INVOLVED IN THE} CONSTRUCTION OF AN UNDERPASS BY ROLLING TECHNIQUE ARE SIMILAR TO CUT AND COVER METHOD EXCEPT THE

\section{FOLLOWING.}

The RCC box segments are casted with rails embedded in the PCC bed.

The lifting brackets, at predetermined locations with Rail pieces, are provided in the RCC box segments.

After insertion of RH girder under traffic block, the existing bank is demolished / dismantled up to the required bed level and made uniform with a well laid PCC bed with rails embedded in line with rails on already laid PCC bed on which the boxes are casted.

For effective rolling of the segments, insertion of rollers and application of grease on the top of embedded rails is ensured.

The RCC box segments are rolled / pushed by means of suitable hydraulic jacks, power packs and placed in position. The necessary reaction is obtained by construction of a thrust beam. All the boxes are placed in similar manner. The alignment and the bed levels of the RCC boxes are monitored by optical instruments at regular intervals.

After placing RCC box segments, RH girder is removed under the traffic block.

\section{REINFORCED CEMENT CONCRETE}

\subsection{Concrete:}

Concrete is a stone like material which is the combination of sand, gravel and few aggregates with water to get harden in the of dimensions.

\subsection{Reinforced Cement Concrete}

$\mathrm{RCC}$ is a strong material with compression and weak in tension, steel is used inside the concrete for mopre strength and interlock for bonding of both the materials.

It $\mathrm{s}$ used in many structural buildings.

\section{MATERIALS USED}

\subsection{Cement:}

Cement is a crushed powder of a stone which is used in all types of constructions.

It has many grades like 33, 43, 53, which has IS 269, IS 112 , IS 12269 respectively.

Cement has two different type:

1. Ordinary Portland cement.

2. Plain cement concrete.

\subsection{Steel}

Steel to be used shall conform to IS: 1786.

It has many different type of sizes like: $6 \mathrm{~mm} 10 \mathrm{~mm}, 12 \mathrm{~mm}$, $16 \mathrm{~mm} . . .32 \mathrm{~mm}$., for the strengthen of building the rod sizes will change.

The new steal is delivered and every bar is inspected before moving it on the slab or work site.

\subsection{Coarse Aggregates}

It is a material which should be clean, hard, dense and durable of crushed stone.

It has different type of sizes which can be tested by flakiness test

\section{ADVANTAGES OF REINFORCED}

\section{CONCRETE}

- It has high compressive strength

- Better resistance to fire than steel.

- Long service life with low maintenance cost.

- In some types of structures, such as dams, piers and footings, it is most economical structural material.

- Yield strength of steel is about 15 times the compressive strength of structural concrete and well over 100 times its tensile strength.

- By using steel, cross sectional dimensions of structural members can be reduced.

\section{DISADVANTAGES OF REINFORCED CONCRETE}

- It needs mixing, casting and curing, all of which affect the final strength of concrete

- The cost of the forms used to cast concrete is relatively high. 
- The compressive strength is very low as co pared to steal, which leads to large sections in beams of multistorey buildings.

\section{SELECTION OF SITE DATA}

- Topography of area.

- Detail cross section considering

- Rail level

- Formation level

- Width of embankment Ground level. Route of signaling cables, electric \&telecom cables.

- Nearest river.

- Trail pit bore details, on embankment, on ground level.

\section{CONCLUSIONS}

- Box pushing work means at least partly working in blind, so problems usually come up during execution of work.

- Box pushing work requires close supervision and monitoring and quite often the unsafe conditions develop at these sites.

- Track must be watched regularly to see signs of heaving, settlement, misalignment etc.

- LWR must be cut and site isolated during box pushing.

- Work must be done under block protection / caution order only.

\section{REFERENCES}

[1]. Principles of Traffic and Highway engineering Garber \& Hoel, Cengagew Learning.

[2]. Principles and Practices of Highway engineering - Dr. L.R.Kadiyali and Dr.N.BLal - Khamnna Publications.

[3]. Highway, railway, Airport and Harbour engineering K.P.Subramanian.

[4]. Harbour, DockTunnel engineering - R. Srinivasan.

[5]. Roads, Railways, Bridges and Tunnel Engineering, T.D.Ahuja \& G.S.Birdi, 16th edition, 2012.

[6]. Elements of Bridge Tunnel and Railway Engineering, S.P.Bindra \& K.Bindra, Reprint 2015.

[7]. Robin et al., 2009 T. Robin, G. Antonini, M. Bierlaire, et al.Specification, estimation and validation of a pedestrian walking behavior model Transportation Research Part B: Methodological, 43 (1) (2009), pp. 36-56

[8]. Jovanis and Chang, 1986 P.P. Jovanis, H.L. Chang Modeling the relationship of accidents to miles traveled Transportation Research Record (1068) (1986), pp. 4251

[9]. AASHTO, 2010, American Association of State Highway and Transportation Officials (AASHTO)Highway Safety Manual (HSM) (First edition)AASHTO, Washington DC (2010)

[10].TRB, 2010 Transportation Research Board (TRB) Highway Capacity Manual 2010 (fifth edition)TRB, Washington DC (2010)

\section{BIOGRAPHIES}

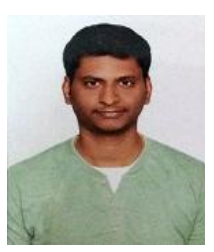

Ranjeet.P holds $M$ Tech Degree in Transportation Engineering from JNTUH, Telangana, India. Presently working as Asst Professor in Civil Department in GNITC, Telangana, India.

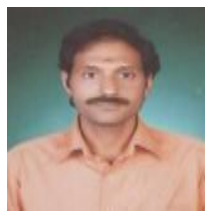

DVS Narashimha Rao, Holds a degree in M sc (Geology), Presently working as Asst Professor in Civil Department in GNITC, Telangana, India.

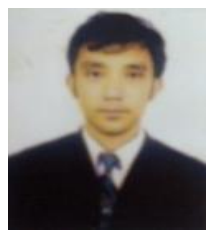

Md. Akramullah Khan, Holds a degree in M sc (Geology), Presently working as Asst Professor in Civil Department in GNITC, Telangana, India. 